\title{
Understanding the Possible Effects of Near and Far Field Tsunamis on Lesser Antilles by Numerical Modeling
}

\author{
Ahmet C. Yalciner*, ${ }^{,}$, Narcisse Zahibo ${ }^{2}$, Efim Pelinovsky ${ }^{3}$, Isil Insel ${ }^{1}$, Derya I. Dilmen ${ }^{1}$, Andrey \\ Zaytsev $^{4}$, Anton Chernov ${ }^{5}$ and Ceren Ozer ${ }^{1}$ \\ ${ }^{I}$ Middle East Technical University, Civil Engineering Department, Ocean Engineering Research Center, 06531 Ankara, \\ Turkey \\ ${ }^{2}$ University of Antilles Guyane, Physics Department, Campus de Fouillole, 97159 Pointe-a-Pitre Cedex, Guadeloupe \\ (F.W.I.), France \\ ${ }^{3}$ Department of Nonlinear Geophysical Processes, Institute of Applied Physics, Russian Academy of Sciences, 46 Ulja- \\ nov Street, Nizhny Novgorod, 603950 Russia \\ ${ }^{4}$ Special Research Bureau for Automation of Marine Researches, Uzhno-Sakhalinsk, Russia \\ ${ }^{5}$ Department of Applied Mathematics, Nizhny Novgorod State Technical University, 603600 Nizhny Novgorod, Russia
}

\begin{abstract}
Results of the numerical modeling of potential tsunamis generated in the center of the Caribbean Sea are given. Numerical modeling is performed with the use of TUNAMI N3 and NAMI DANCE. The maximum amplitude of the water elevation in Lesser Antilles can reach upto 3-4m. The travel time of tsunami is 1.5 hours to Northern islands of Lesser Antilles and 2 hours to Southern islands of Lesser Antilles. It must also be noted that the southern coast of Caribbean Sea will be much more effected comparing to the Lesser Antilles when a tsunami is generated in the center of the Caribbean Sea.
\end{abstract}

Keywords: Tsunami, shallow water theory, numerical modelling, lesser antilles.

\section{INTRODUCTION}

The possible effects of near and far field tsunamis on Lesser Antilles is an important issue when the history of tsunamis in the Caribbean is considered. Numerical modelling is also an important tool for the assesment of the tsunami effects on the coastal areas. For that purpose, the numerical simulations of tsunamis in Caribbean are performed using the numerical models TUNAMI N3 and NAMI DANCE in the region for a selected tsunami scenario. The simulation duration is taken as 5 hours and snapshots of sea surface in 1 hour intervals are plotted. The propagation and directivity of the tsunami are computed and also presented. The time histories of water surface fluctuations at selected gauge locations are also computed and the results are discussed.

\section{ASSESMENT OF TSUNAMI EFFECTS IN LESSER ANTILLES BY NUMERICAL MODELING}

The Caribbean Sea is an active tectonic region and there are active faults which may generate tsunamis. The source mechanisms of the possible tsunamis in the region have been evaluated in [1-5]. A possible tsunami source in the center of the Caribbean (Fig. 1) has not been simulated. Even if this source has not been considered as having priority

*Address correspondence to this author at the Middle East Technical University, Civil Engineering Department, Ocean Engineering Research Center, 06531 Ankara, Turkey; Tel: 903122105438; Fax: 903122101800 ;

E-mail: yalciner@metu.edu.tr since the active fault in this location has not been studied and defined clearly. But the location being in the center of the Caribbean may be important for all coastal areas in the Caribbean if a tsunami is generated in this region. The rupture characteristics considering a thrust fault is selected for a tsunami source in this location. The selected rupture characteristics of a possible tsunami are listed in Table 1. By using these rupture characteristics, the initial wave is generated using the tsunami modeling software NAMI DANCE [6-13]. The location of the initial source is shown in Fig. (1).

The simulations are performed by the modeling software TUNAMI N3 using the nested domains. The boundaries and other parameters of three nested domains named as B (largest), C (medium) and D (small) are given in Table $\mathbf{2}$ and shown on Figs. $(\mathbf{1}, \mathbf{2}, \mathbf{3})$. As seen from Table 2, the grid resolution is selected as $3600 \mathrm{~m}, 1200 \mathrm{~m}$ and $400 \mathrm{~m}$ respectively for the domains B, and C and D. In order to monitor the sea surface fluctuations near the selected coastal areas in Lesser Antilles, several gauges are located at the selected regions. The locations of the gauges are shown in Fig. (4).

NAMI DANCE is a computational tool developed by Andrey Zaytsev, Ahmet Yalciner, Anton Chernov, Efim Pelinovsky and Andrey Kurkin especially for tsunami modeling. It provides direct simulation and efficient visualization of tsunamis to the user and for the assessment, understanding and investigation of tsunami generation and propagation mechanisms. It is developed by $\mathrm{C}++$ programming language by following leap frog scheme numerical solution proce- 
Table 1. Selected Rupture Characteristics of the Simulated Possible Tsunami in Caribbean

\begin{tabular}{|c|c|}
\hline Epicenter of Fault Axis & Lat= 73W Lon= 16N \\
\hline \hline Length of fault (km) & 120 \\
\hline Strike angle (deg. CW) & 35 \\
\hline Width of fault (km) & 10 \\
\hline Focal depth (km) & 10 \\
\hline Dip angle (degree) & 110 \\
\hline Slip angle (degree) & 10 \\
\hline Displacement (m) & 5.1 \\
\hline Height of initial wave (m) & 3.2 \\
\hline Maximum positive amplitude (m) & 1.9 \\
\hline Maximum negative amplitude $(\mathrm{m})$ & \\
\hline
\end{tabular}

Table 2. Study Domains for Simulations

\begin{tabular}{|c|c|c|c|c|}
\hline Name & Coordinate & Grid Size (m) & $\begin{array}{c}\text { Simulation Time Step } \\
\text { (sec) }\end{array}$ & $\begin{array}{c}\text { Output Time } \\
\text { Intervals (sec) }\end{array}$ \\
\hline \hline Domain B & $89 \mathrm{~W}, 58 \mathrm{~W}$ & 3600 & 6 & 24 \\
(hours) & $5 \mathrm{~N}, 22.5 \mathrm{~N}$ & 2 & 24 \\
\hline Domain C & $63.4 \mathrm{~W}, 59.3 \mathrm{~W}$ & 1200 & 5 \\
\hline
\end{tabular}

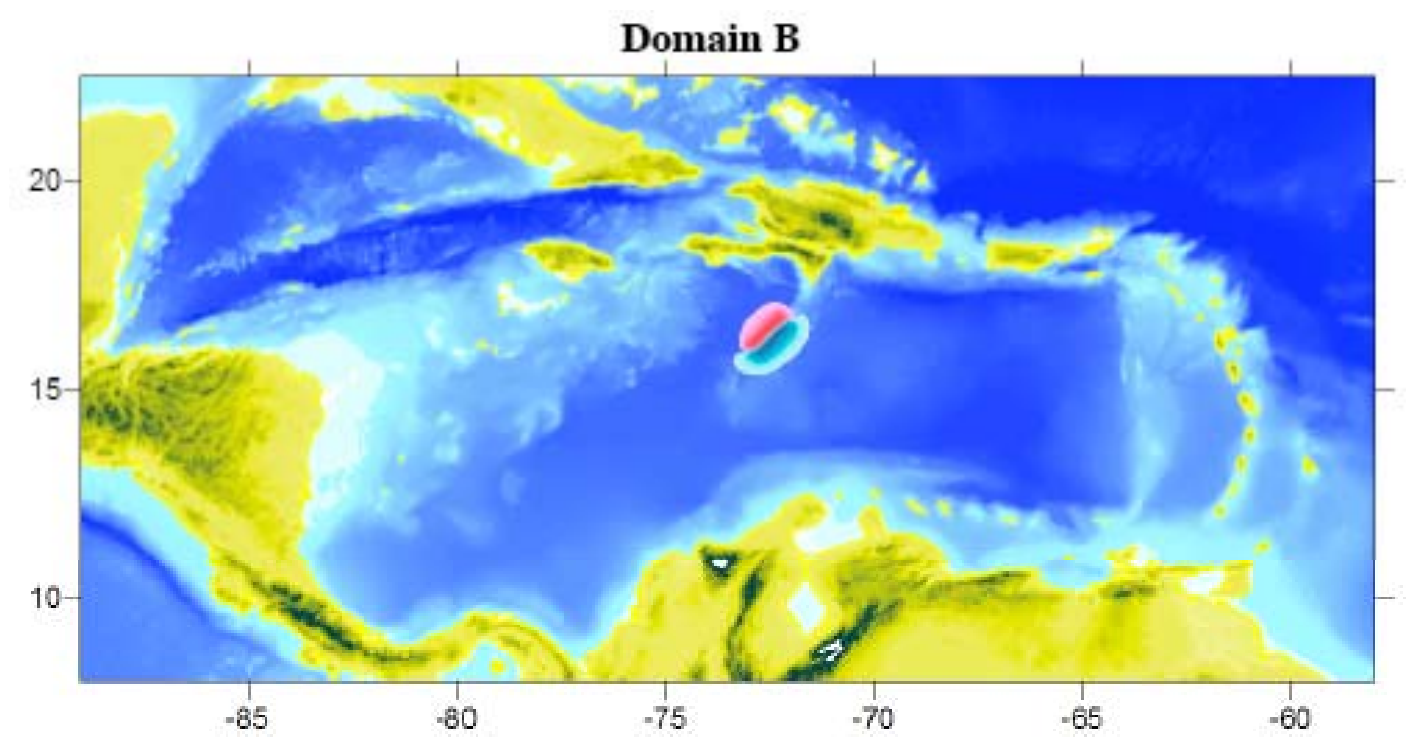

Fig. (1). Source of given earthquake rupture characteristics and Bathymetry of Domain B.

dures [6] and has several modules for development of all requirements.

NAMI DANCE computes i) tsunami source from either rupture characteristics or pre-determined wave form, ii) propagation, iii) arrival time, iv) coastal amplification v) inundation (according to the accuracy of grid size), vi) dis- tribution of current velocities and their directions at selected time intervals, vii) distribution of water surface elevations (sea state) at selected time intervals, viii) relative damage levels according to drag force and impact force, ix) time histories of water surface fluctuations, $x$ ) 3D plot of sea state at selected time intervals from different camera and light posi- 


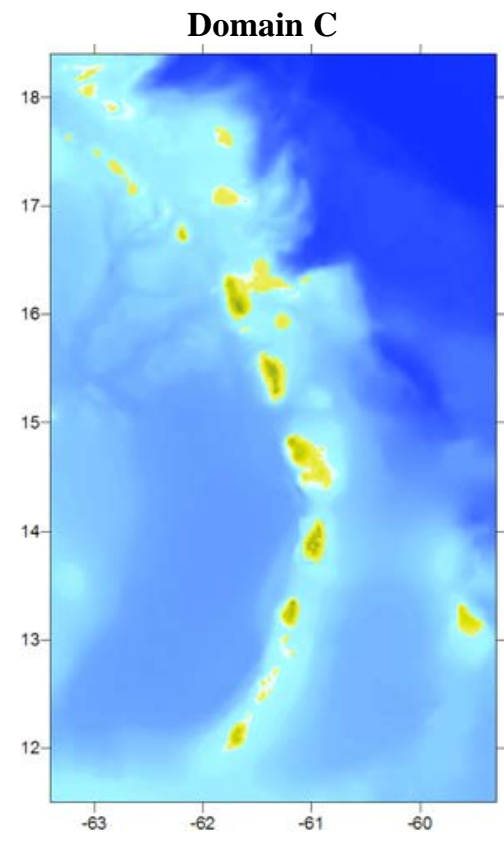

Fig. (2). Bathymety of Domain C.

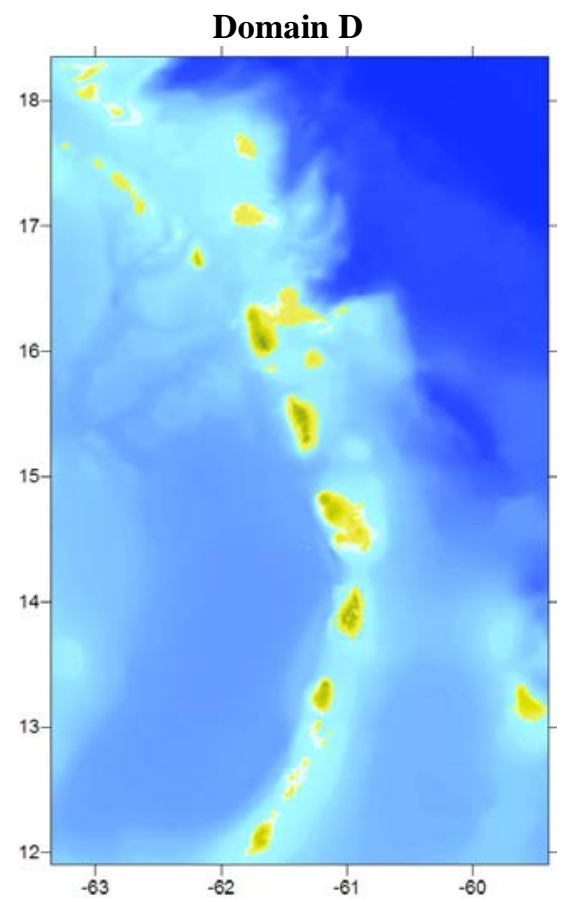

Fig. (3). Bathymetry of Domain D.

tions, and xi) animation of tsunami propagation between source and target regions [12-14]. For more detail: (http://namidance.ce.metu.edu.tr/).

Tsunami numerical modeling is based on the solution of nonlinear form of the long wave equations with respect to related initial and boundary conditions. There were several numerical solutions of long wave equations for tsunamis. In general the explicit numerical solution of Nonlinear Shallow Water (NLSW) Equations is preferable for the use since it uses reasonable computer time and memory, and also provides the results in acceptable error limit. The most impor-

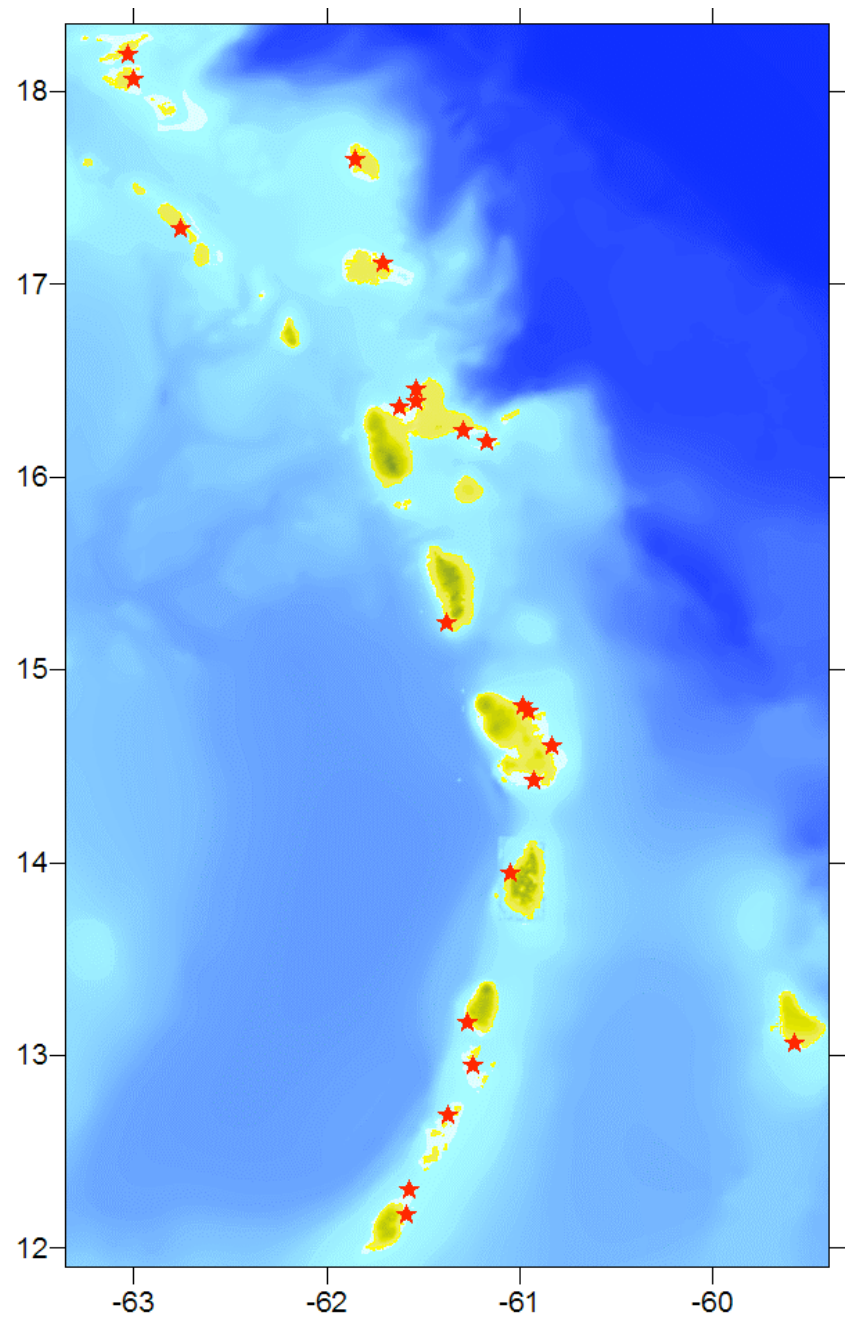

Fig. (4). Gauge point locations.

tant development in tsunami modeling has been achieved by Profs. Shuto and Imamura by developing model TUNAMI $N 2$. It was opened to the use of tsunami scientists under the umbrella of UNESCO [15-17]. TUNAMI N3 is the advanced version of TUNAMI N3. It determines the tsunami source characteristics from earthquake rupture characteristics and run-up on land in three nested domains. It computes all necessary parameters of tsunami motion in shallow water and in the inundation zone allowing for a better understanding of the effect of tsunamis according to bathymetric and topographical conditions.

The codes are cross tested and also verified in international workshops specifically organized for testing and verifications of tsunami models [14-16]. As for the tsunami parameters, the numerical modeling was applied by using the tsunami numerical codes TUNAMI N3 and NAMI DANCE to the selected rupture to investigate the probable tsunami effect in the Lesser Antilles for 5 hours simulation duration. The sea state in the Domains B, C and D are computed and plotted for the time $\mathrm{t}=0, \mathrm{t}=1 \mathrm{hr}, \mathrm{t}=2 \mathrm{hr}, \mathrm{t}=3 \mathrm{hr}, \mathrm{t}=4 \mathrm{hr}$, and $\mathrm{t}=5 \mathrm{hr}$ together with the maximum positive and negative wave amplitudes in Figs. (5-8). The time histories of the water surface fluctuations at selected gauge points are also shown in Figs. (9-11). As seen from these figures that the 

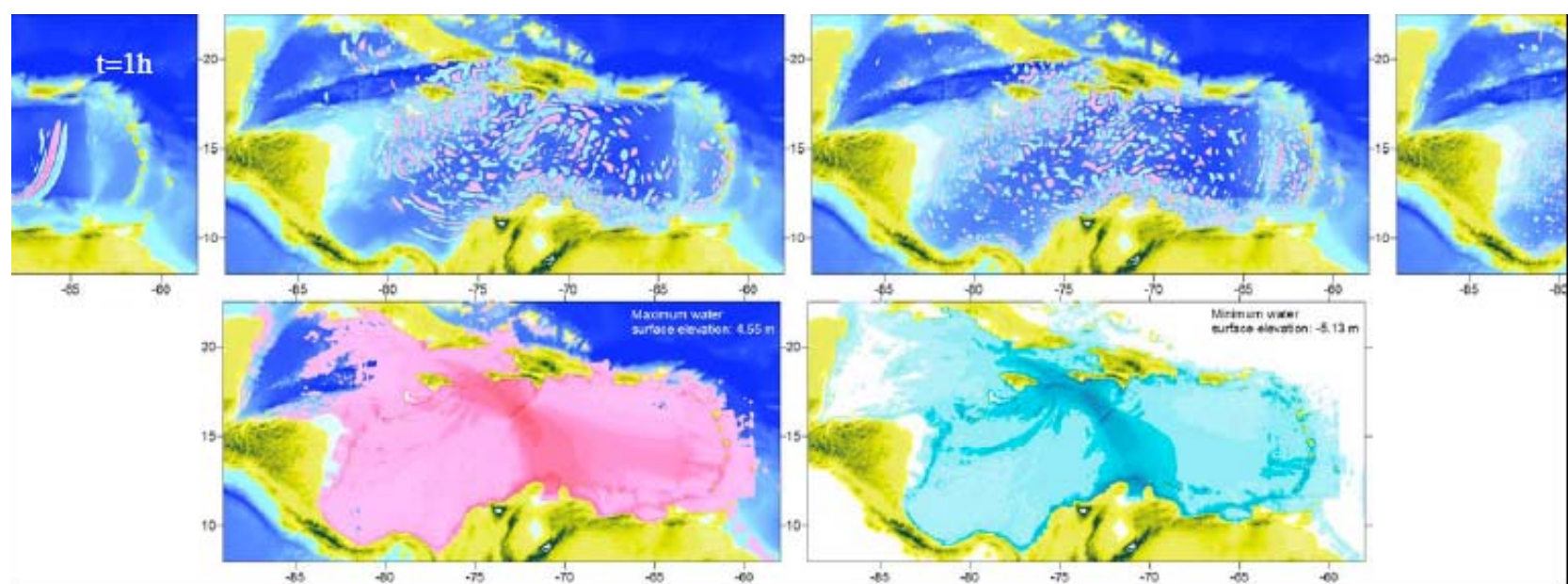

Fig. (5). The sea state at different time steps ( $t=0,1,2,3,4$ and 5 hours), the maximum positive and negative wave amplitudes in the Domain B: Maximum positive amplitude $4 . \mathrm{m}$ and maximum negative amplitude is $-5.2 \mathrm{~m}$.
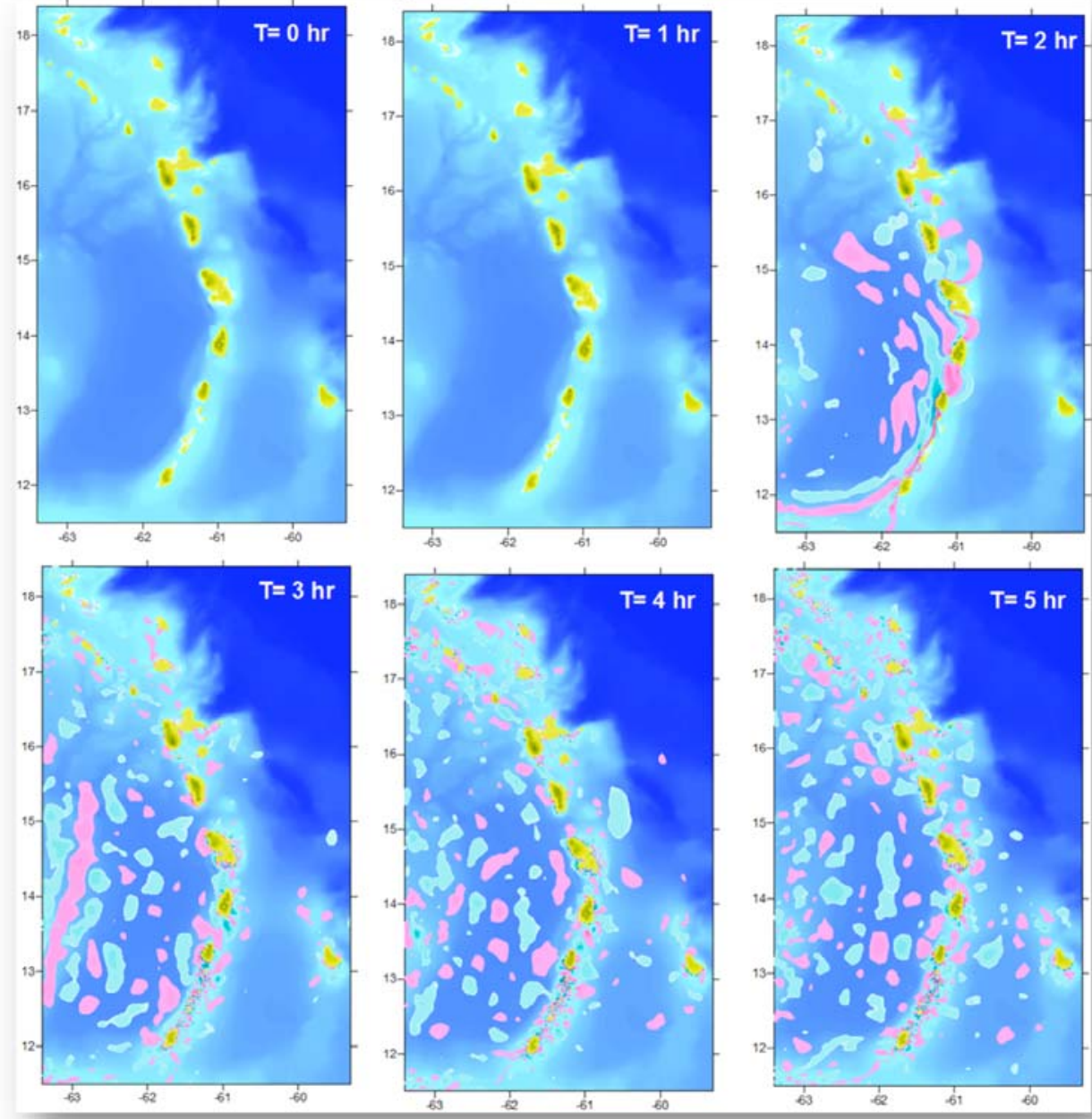

Fig. (6). The sea state for different time steps ( $\mathrm{t}=0,1,2,3,4$ and 5 hours) in Domain $\mathrm{C}$.

maximum amplitude of the water elevation in the study domain (Domain D) in Lesser Antilles is about 3-4 m. Among the selected gauge location the higher positive amplitude of tsunami waves are obtained in Saint Lucia. The arrival time of tsunami if generated in the center of Caribbean sea, is 1.5 hours to North islands of Lesser Antilles and 2 hours to South islands of Lesser Antilles.

\section{DISCUSSIONS OF THE RESULTS}

The possible effects of near and far field tsunamis generated from the center of Caribbean sea is investigated by applying the numerical models TUNAMI N3 and NAMI DANCE to the Caribbean sea and Lesser Antilles. According to the 5 hours simulation, it is computed that maximum 

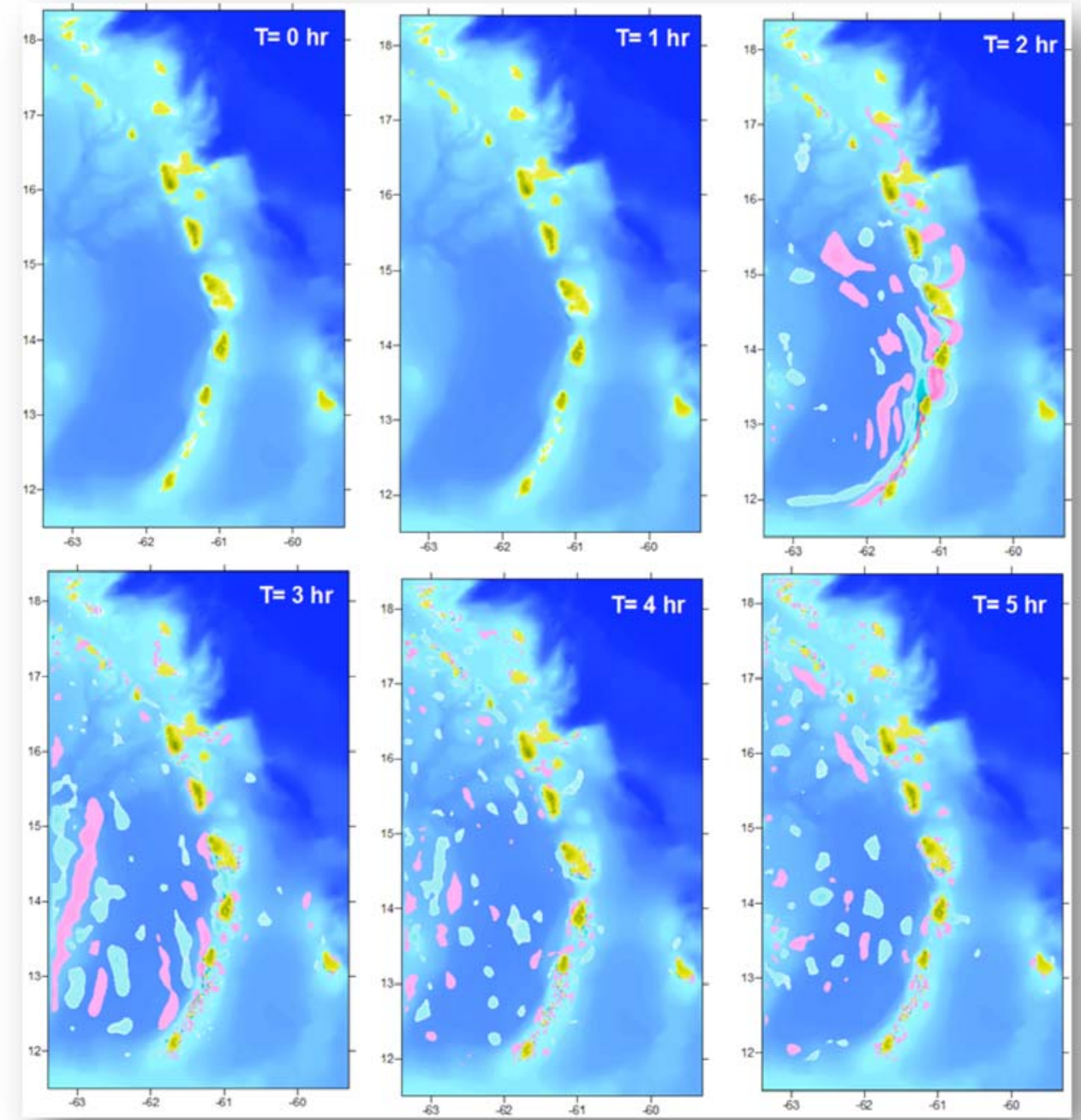

Fig. (7). The sea state at different time steps ( $\mathrm{t}=0,1,2,3,4$, and 5 hours) for Domain $\mathrm{D}$.
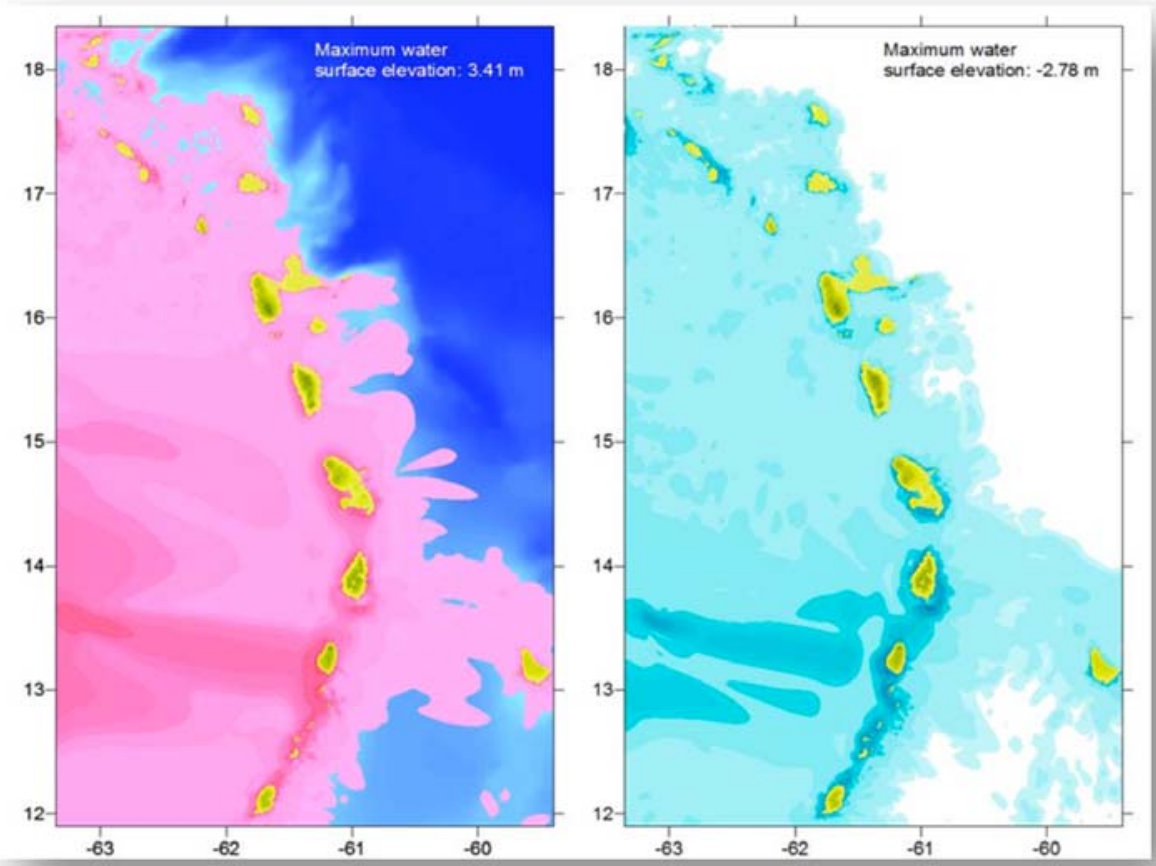

Fig. (8). Maximum positive and negative wave amplitudes in the Domain D : maximum positive amplitude is $3.4 \mathrm{~m}$ maximum negative amplitude is $-2.8 \mathrm{~m}$. 


\subsection{Time Histories}

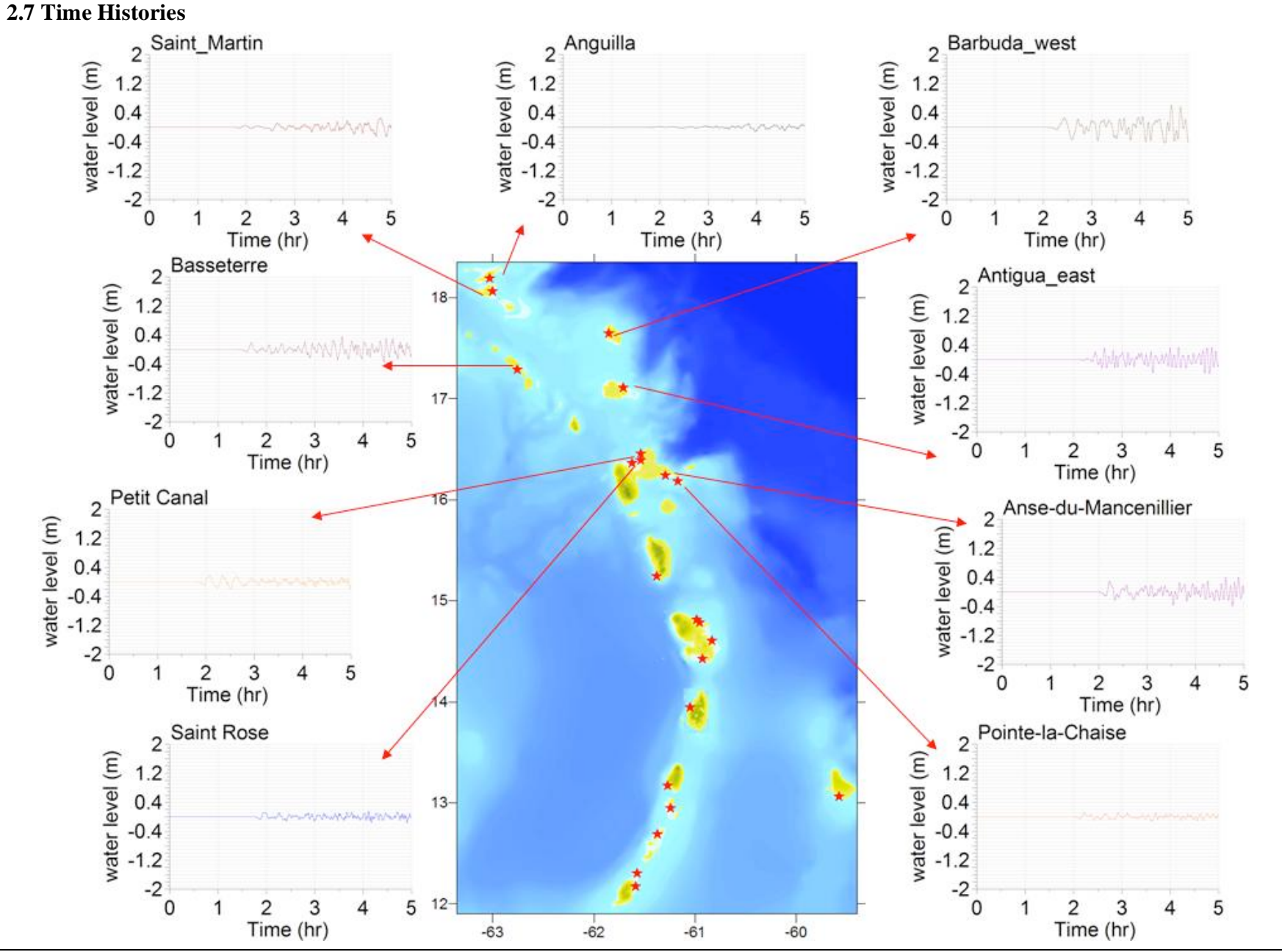

Fig. (9). The time histories of water surface elevations for selected gauge points in Northern Lesser Antilles.

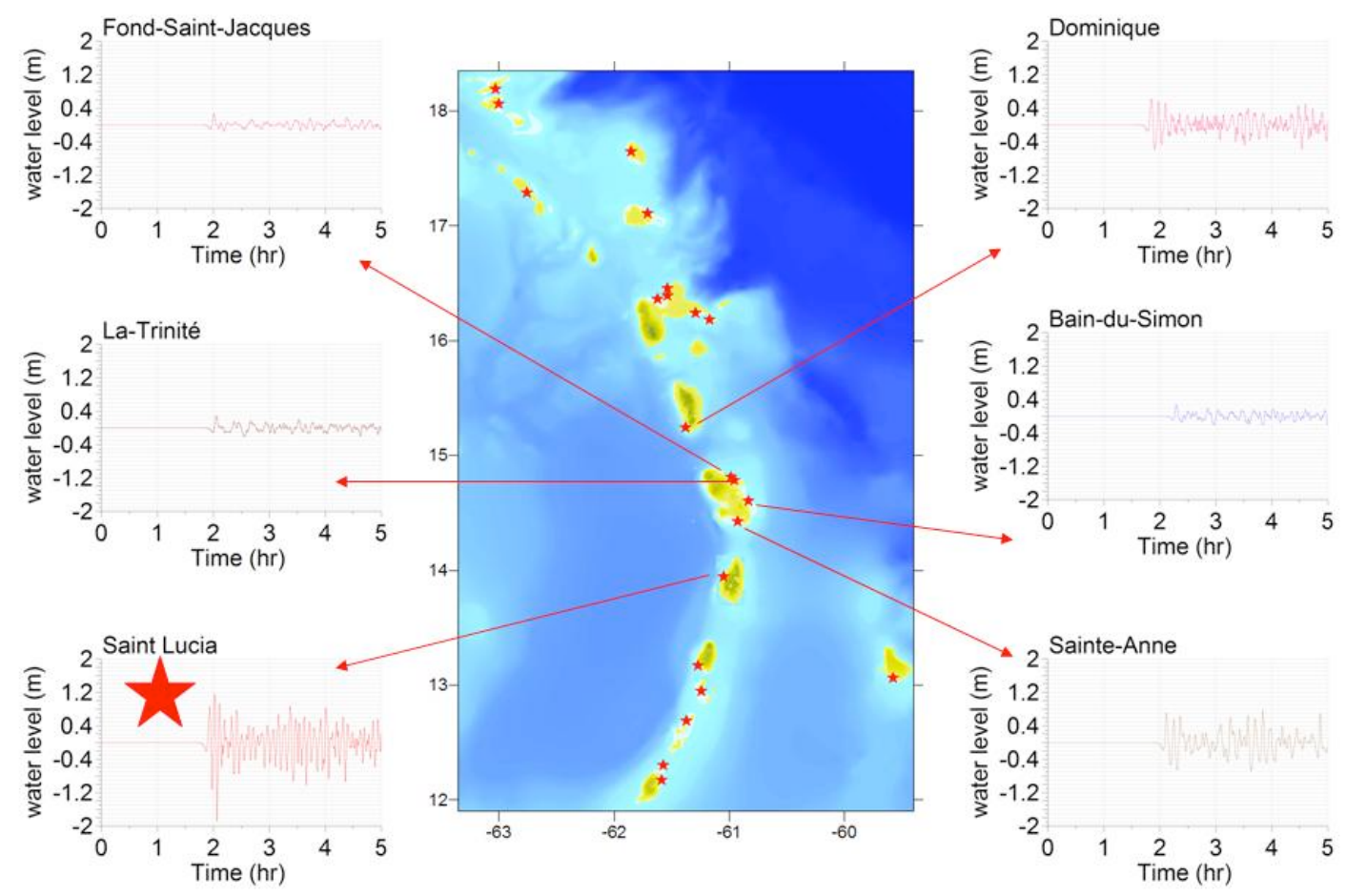

Fig. (10). The time histories of water surface elevations for selected gauge points in Southern Lesser Antilles. 


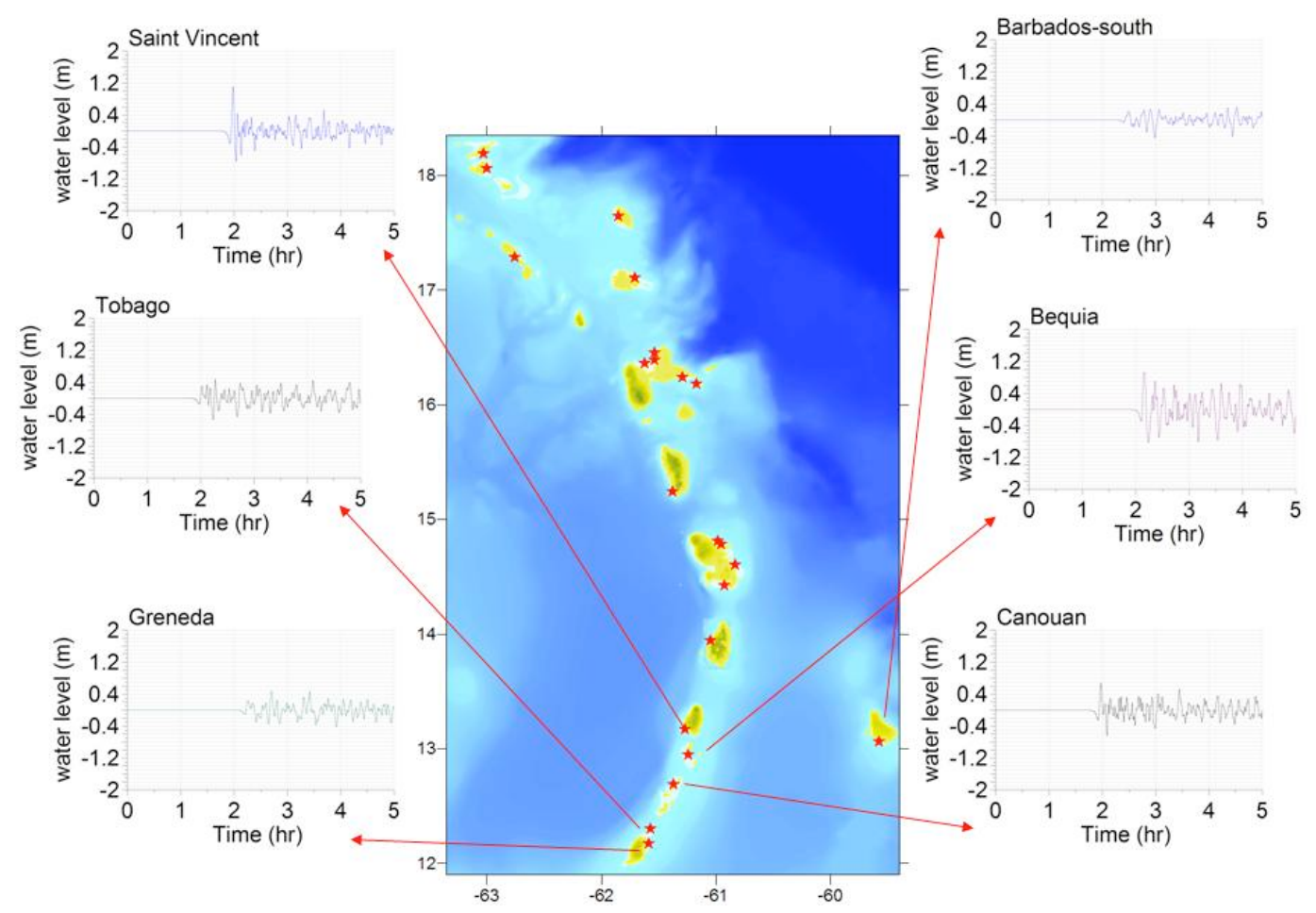

Fig. (11). The time histories of water surface elevations for selected gauge points in lesser Antilles.

amplitude of the water elevation in the study domain in Lesser Antilles is about $3-4 \mathrm{~m}$. The arrival time of tsunami if generated in the center of Caribbean Sea is 1.5 hours to Northern islands of Lesser Antilles and 2 hours to Southern islands of Lesser Antilles. It must also be noted that the southern coast of Caribbean sea will be much more effected comparing to the Lesser Antilles.

\section{ACKNOWLEDGEMENTS}

Prof. Dr. Nobuo Shuto, Prof. Dr. Fumihiko Imamura, Prof. Dr. Costas Synolakis and Prof. Dr. Emile Okal are acknowledged for their long term, close cooperation, discussion and collaboration during the development of the models used in this study. The authors also acknowledge partial support of TUBITAK (Turkey) through grant 09-0591222-CT_a, UNESCO-IOC and INTAS Ref. Nr 05-1095100 for development of the code. EP, AZ and AC thank the RFBR grants (08-05-00069, 09-05-00971a, 09-05-90706mob and 09-05-00591). This study is also partly supported by the Projects TRANSFER (Tsunami Risk and Strategies for the European Region) supported by the CEC, contract in 037058, FP6-2005-Global-4 and SEAHELLARC Project granted by European Commission.

\section{REFERENCES}

[1] Kurkin AA, Kozelkov A, Zaitsev AI, Zahibo N, Yalciner A. Tsunami risk for the Caribbean Sea Coast. Izvestiya Russ Acad Eng Sci 2003; 4: 126-49.

[2] Zahibo N, Pelinovsky E, Yalciner AC, Kurkin A, Koselkov A, Zaitsev A. The 1867 Virgin Island tsunami: observations and modeling. Oceanol Acta 2003a; 26(5-6): 609-21.

[3] Zahibo N, Pelinovsky E, Yalciner AC, Kurkin A, Koselkov A, Zaitsev A. The 1867 Virgin Island Tsunami. Nat Hazards Earth Syst Sci 2003b; 3: 367-76.
[4] Zahibo N, Pelinovsky E, Kurkin A, Kozelkov A. Estimation of farfield tsunami potential for the Caribbean Coast based on numerical simulation. Sci Tsunami Hazards 2003c; 21(4): 202 - 22.

[5] Zahibo N, Pelinovsky E, Yalciner AC, et al. Trans-Atlantic propagation of 1755 Tsunami and its effects on the french west indies. Ocean Eng 2009 (in review).

[6] Goto C, Ogawa Y. Numerical method of tsunami Simulation with the leap-frog scheme, translated for the TIME Project by Prof. Shuto N, Disaster Control Research Center. Faculty of Enggineering, To-hoku University, Sendai, Japan 1991.

[7] Imamura F. Tsunami numerical simulation with the staggered leap-frog scheme (Numerical code of TUNAMI-N1), School of Civil Engineering, Asian Institute of Technology and Disaster Control Research Center, Tohoku University 1989.

[8] Shuto N, Goto C, Imamura F. Numerical simulation as a means of warning for near field tsunamis. Coast Eng Japan 1990; 33: 17393.

[9] Okada Y. Surface deformation due to shear and tensile faults in a half-space. Bull Seismol. Soc Am 1985; 75: 1135-54.

[10] Yalciner AC, Kuran U, Akyarli A, Imamura F. An investigation on the generation and propagation of tsunamis in the aegean sea by mathematical modeling, "Tsunami: Progress in Prediction, Disaster Prevention and Warning", in the book series of Advances in Natural and Technological Hazards Research. In: Yashuito T, Nobuo S, Eds. USA: Kluwer Academic Publishers 19995; pp. 55-71.

[11] Yalciner AC, Pelinovsky E, Zaytsev A, Kurkin A, Ozer C, Karakus H. Modeling and visualization of tsunamis: Mediterranean examples, from Nonlinear Waves and Tsunamis. Kondu A, Ed. New York: Springer 2007.

[12] Yalciner AC, Synolakis CE, Gonzales M. Joint Workshop on Tsunami Modeling, Inundation and Applications to Test Sites in Project TRANSFER" Workshop organized in TRANSFER Project in June 14-16, 2007, Fethiye Turkey.

[13] Yalciner AC, Imamura F, Synolakis CE. Amplitude evolution and runup of long waves: comparison of experimental and numerical data, Advances in coastal and ocean engineering advanced numerical models; world scientific singapore Eds: Liu, L.-F. P. Yeh, H., Synolakis, C. 2008; 10: 243-7.

[14] Zahibo N, Pelinovsky E, Yalciner A C, et al. Trans-Atlantic Propagation of 1755 Tsunami and its effects on the french west indies. Ocean Eng 2009; (in review). 
[15] Synolakis CE, Liu F, Yeh H. NSF Workshop on Long Wave Runup Models Catalina, LA, USA 2004.

[16] Liu PLF, Yeh H, Synolakis CE. Advances in coastal and ocean engineering advanced numerical models; World scientific Singapore 2008 .
[17] Yalciner AC, Pelinovsky E, Zaytsev A, Kurkin A, Ozer C, Karakus H. NAMI DANCE Manual 2006; METU, Civil Engineering Department, Ocean Engineering Research Center, Ankara, Turkey Available from: http://namidance.ce.metu.edu.tr

(C) Yalciner et al.; Licensee Bentham Open.

This is an open access article licensed under the terms of the Creative Commons Attribution Non-Commercial License (http://creativecommons.org/licenses/ by-nc/3.0/) which permits unrestricted, non-commercial use, distribution and reproduction in any medium, provided the work is properly cited. 